\title{
Injectable and Temperature-Sensitive Titanium Carbide-Loaded Hydrogel System for Photothermal Therapy of Breast Cancer
}

\author{
Jun $\mathrm{Yao}^{1 \dagger}$, Chuanda Zhu ${ }^{2 \dagger}$, Tianjiao Peng ${ }^{1}$, Qiang $\mathrm{Ma}^{3 *}$ and Shegan $\mathrm{Gao}^{1 *}$ \\ ${ }^{1}$ Henan Key Laboratory of Cancer Epigenetics, Cancer Institute, The First Affiliated Hospital, College of Clinical Medicine of Henan \\ University of Science and Technology, Luoyang, China, ${ }^{2}$ School of Basic Medical Sciences, Peking University Health Science \\ Center, Beijing, China, ${ }^{3}$ Institute of Environment and Sustainable Development in Agriculture, Chinese Academy of Agricultural \\ Sciences, Beijing, China
}

OPEN ACCESS

Edited by: Jijun $F u$,

Guangzhou Medical University, China

Reviewed by:

Wenjie Chen,

Royal North Shore Hospital, Australia

Teng Gong,

Guangzhou Medical University, China

Lingmin Zhang,

Guangzhou Medical University, China

${ }^{*}$ Correspondence:

Shegan Gao

gsg1258@126.com

Qiang Ma

82101199301@caas.cn

${ }^{\dagger}$ These authors have contributed equally to this work and share first

authorship

Specialty section: This article was submitted to

Nanobiotechnology,

a section of the journal Frontiers in Bioengineering and

Biotechnology

Received: 09 October 2021

Accepted: 25 November 2021

Published: 23 December 2021

Citation:

Yao J, Zhu C, Peng T, Ma Q and Gao S (2021) Injectable and TemperatureSensitive Titanium Carbide-Loaded Hydrogel System for Photothermal

Therapy of Breast Cancer.

Front. Bioeng. Biotechnol. 9:791891.

doi: 10.3389/fbioe.2021.791891
Recently, organic-inorganic hybrid materials have gained much attention as effective photothermal agents for cancer treatment. In this study, Pluronic F127 hydrogel-coated titanium carbide $\left(\mathrm{Ti}_{3} \mathrm{C}_{2}\right)$ nanoparticles were utilized as an injectable photothermal agent. The advantages of these nanoparticles are their green synthesis and excellent photothermal efficiency. In this system, lasers were mainly used to irradiate $\mathrm{Ti}_{3} \mathrm{C}_{2}$ nanoparticles to produce a constant high temperature, which damaged cancer cells. The nanoparticles were found to be stable during storage at low temperatures for at least 2 weeks. The $\mathrm{Ti}_{3} \mathrm{C}_{2}$ nanoparticles exhibited a shuttle-shaped structure, and the hydrogels presented a loosely meshed structure. In addition, $\mathrm{Ti}_{3} \mathrm{C}_{2}$ nanoparticles did not affect the reversible temperature sensitivity of the gel, and the hydrogel did not affect the photothermal properties of $\mathrm{Ti}_{3} \mathrm{C}_{2}$ nanoparticles. The in vitro and in vivo results show that this hydrogel system can effectively inhibit tumor growth upon exposure to nearinfrared irradiation with excellent biocompatibility and biosafety. The photothermal agentembedded hydrogel is a promising photothermal therapeutic strategy for cancer treatment by enhancing the retention in vivo and elevating the local temperature in tumors.

Keywords: pluronic $\mathrm{F} 127$ hydrogel, photothermal therapy, anti-cancer, thermosensitive, $\mathrm{Ti}_{3} \mathrm{C}_{2}$ nanoparticles

\section{INTRODUCTION}

Photothermal therapy (PTT) has been widely used in cancer therapy because of its excellent antitumor effects (Senapati et al., 2018; Zhi et al., 2020). In PTT, a near-infrared (NIR: $700-1,100 \mathrm{~nm}$ ) laser is used to irradiate the target area where a PTT agent is present. This produces a constant high temperature $\left(40^{\circ} \mathrm{C}-50^{\circ} \mathrm{C}\right)$, which either induces the death of local cancer cells or increases their sensitivity to other therapies (Chen et al., 2017; Yu et al., 2017; Zhao et al., 2018; Lu et al., 2020). PTT has shown significant therapeutic effects in various antitumor studies (Jiang et al., 2018; Zhu et al., 2018; Chen et al., 2019a). Many photothermal agents (PTAs) have been developed to convert the energy of NIR lasers into heat for cancer research, including organic dye molecules (Sahu et al., 2016), precious metal materials (Xu et al., 2019), carbon-based materials (Liu et al., 2019a; Rafieerad et al., 2019), and other inorganic materials (Popescu et al., 2011). PTA is often administered intravenously (Popescu et al., 2011; Jiang et al., 2018; Zhang et al., 2018; Zhi et al., 2020). However, there are some concerns regarding the toxicity of intravenously 
administered PTAs. Most PTAs contain heavy metals. In addition, the inherent instability of organic agents limits their therapeutic effects. For example, indocyanine green often undergoes light bleaching and is rapidly eliminated after intravenous administration (Sahu et al., 2016; Chen et al., 2017; Yu et al., 2017).

Therefore, nanomaterials with good photothermal stability have been designed to overcome the limitations of traditional PTAs by using an NIR laser to increase the temperature (Chen et al., 2019b; He et al., 2019; Xu et al., 2019; Zhao et al., 2019; He et al., 2020; Wang et al., 2020). As an outstanding nanomaterial, titanium carbide $\left(\mathrm{Ti}_{3} \mathrm{C}_{2}\right)$ shows good performance in the anticancer field of PTT. For example, $\mathrm{Ti}_{3} \mathrm{C}_{2}$ can absorb large amounts of light and shows high light-thermal conversion efficiency and high biocompatibility at NIR wavelengths. Photothermal nanomaterials can be actively concentrated in tumor tissues by modifying the nanoparticle surface to avoid systemic toxicity (He et al., 2019; Zhao et al., 2019). The treatment conditions (laser power, exposure positions, and exposure times) can be artificially controlled to minimize damage to the surrounding healthy tissue. In addition, photothermal nanomaterials can be actively targeted to tumor sites using ultrasonic or magnetic guidance (Senapati et al., 2018; Chen et al., 2019b). However, nanomaterials with targeted functions not only require costly materials and complex operations but also have a short half-life in the body (Xu et al., 2019; He et al., 2020; Liu et al., 2020; Lu et al., 2020). Thus, a simple and effective local slow-release administration system for PTT is urgently needed.

Currently, commonly used intratumoral or peritumoral sustained-release delivery systems include microneedles ( $\mathrm{Yu}$ et al., 2020) and hydrogels (Fu et al., 2019; Geng et al., 2020), which can prolong drug release into the targeted tissue. For example, in situ gels contain a drug loaded in a specific polymer carrier. In situ gels adopt a sol form in vitro and quickly form a gel after administration in vivo, prolonging drug retention in the tumor (Liu et al., 2017; Geng et al., 2020). The gel formation mechanism can be illustrated by Pluronic F127 (F127), a three-segment copolymer that consists of polyoxymethylene and polyoxypropylene. At low temperatures, F127 exists as a single molecule. As the temperature increases, the hydrophobic fragments of polyoxypropylene in the F127 molecule dehydrate to form spherical gel beams consisting of an inner core of hydrophobic polyoxypropylene and external swollen polyoxyethylene. Subsequently, the stacked bundles further wind to form a gel (Chen et al., 2019a; Russo and Villa, 2019; Yu et al., 2021). As a mild-sensitized pharmaceutical accessory, F127 limits the random dispersion of nanoparticles within tissues to avoid damage to normal tissues (Fu et al., 2019).

To effectively treat breast cancer and reduce the side effects of traditional PTA, we designed an injectable and temperaturesensitive $\mathrm{F} 127$ hydrogel mixed with $\mathrm{Ti}_{3} \mathrm{C}_{2}$ nanoparticles. The $\mathrm{Ti}_{3} \mathrm{C}_{2}$ nanoparticles and temperature-sensitive F127 hydrogel jointly construct the $\mathrm{Ti}_{3} \mathrm{C}_{2}$-Gel system, which is administered by local injection at low temperatures and forms a gel at $37^{\circ} \mathrm{C}$ in the body. The results of in vivo and in vitro experiments showed that the system had an excellent antitumor effect. In general, the combination of $\mathrm{Ti}_{3} \mathrm{C}_{2}$ nanoparticles and temperature-sensitive hydrogels is a promising antitumor local administration system with the potential for use in clinical cancer treatments.

\section{MATERIALS AND METHODS}

\section{Materials}

$\mathrm{Ti}_{3} \mathrm{C}_{2}$ MXene solution was purchased from Beike 2D Materials Co., Ltd. (Beijing, China). Pluronic F127 was purchased from Sigma (St. Louis, MO, USA). Dulbecco's modified Eagle's medium (DMEM) and fetal bovine serum were purchased from Gibco (Grand Island, NY, USA). The Cell Counting Kit8 (CCK-8) was obtained from Dojindo Laboratories (Kumamoto, Japan). The hematoxylin-eosin staining kit (H\&E) and terminal deoxynucleotidyl transferase-mediated dUTP nick end labeling (TUNEL) kit were purchased from Solarbio (Beijing, China). All other reagents were analytically pure and used without further purification. Deionized water was used in this study.

\section{Cell and Mice}

Mouse breast cancer cells (4T1 cells) were obtained from the American Type Culture Collection (Manassas, VA, USA) and cultured in DMEM containing $1 \%$ penicillin-streptomycin and $10 \%$ fetal bovine serum at $37^{\circ} \mathrm{C}$ under a $5 \% \mathrm{CO}_{2}$ atmosphere. Female BALB/c mice (6-8 weeks of age) were obtained from Charles River Laboratories (Wilmington, MA, USA) for animal experiments. All animal experiments were approved by the Animal Care and Use Committees at the First Affiliated Hospital and College of Clinical Medicine of Henan University of Science and Technology.

\section{Preparation and Characterization of $\mathrm{Ti}_{3} \mathrm{C}_{2}$-Gel}

The $\mathrm{Ti}_{3} \mathrm{C}_{2}$-Gel system was fabricated using a simple mixture. $\mathrm{Ti}_{3} \mathrm{C}_{2}$ nanoparticles were obtained through ultrasonic treatment of $\mathrm{Ti}_{3} \mathrm{C}_{2}$ MXene solution. The $\mathrm{Ti}_{3} \mathrm{C}_{2}$ nanoparticles and thermosensitive Pluronic F127 were mixed to prepare the PTA-embedded hydrogel system (Figure 1). The F127 powder was dissolved in water to form hydrogels with different concentrations $(40 \%, 35 \%, 30 \%, 25 \%, 20 \%, 19 \%$, and $18 \%)$. To obtain different final concentrations of $\mathrm{Ti}_{3} \mathrm{C}_{2}$ nanoparticles embedded in F127 hydrogels $\left(\mathrm{Ti}_{3} \mathrm{C}_{2}: 400,200,100,50\right.$, and $25 \mu \mathrm{g} / \mathrm{ml}$; F127 hydrogels: 20\%), a solution of $\mathrm{Ti}_{3} \mathrm{C}_{2}$ nanoparticles was added to the 20\% F127 hydrogels. These hydrogels (including $\mathrm{Gel}$ and $\mathrm{Ti}_{3} \mathrm{C}_{2}$-Gel) were stored at $4{ }^{\circ} \mathrm{C}$ until use. After dilution by 50 -fold with pure water, the size and zeta potential of these samples $\left(\mathrm{Ti}_{3} \mathrm{C}_{2}\right.$ and $\mathrm{Ti}_{3} \mathrm{C}_{2}$-Gel) were measured by dynamic light scattering (PSS ZPW 388, Nicomp, Orlando, FL, USA). The appearance of these samples was recorded using transmission electron microscopy (JEOL174 1200EX, Tokyo, Japan).

To determine the phase change temperature of the hydrogels, different concentrations of blank F127 gel (40\%, 35\%, 30\%, 25\%, $20 \%, 19 \%, 18 \%)$ and $\mathrm{Ti}_{3} \mathrm{C}_{2}-\mathrm{Gel}\left(\mathrm{Ti}_{3} \mathrm{C}_{2}: 50 \mu \mathrm{g} / \mathrm{ml}\right)$ were added to glass bottles and placed at $4{ }^{\circ} \mathrm{C}$ to maintain the liquid state to 
remove bubbles from the samples. During this assay, an agitator was placed in the bottles, which were placed in a water bath under a tunable temperature and magnetic stirring. The heating rate was $0.5^{\circ} \mathrm{C} / \mathrm{min}$, and the rotation rate of the magnetic agitator was $300 \mathrm{rpm}$. The temperature was recorded as the gel formation temperature when the agitator was completely stopped. Each sample was measured three times.

In addition, the rheumatic behaviors of blank F127-Gel (20\%) and $\mathrm{Ti}_{3} \mathrm{C}_{2}$-Gel $\left(\mathrm{Ti}_{3} \mathrm{C}_{2}: 50 \mu \mathrm{g} / \mathrm{ml} ; 20 \% \mathrm{~F} 127 \mathrm{Gel}\right)$ were observed using a rheometer (MCR92, Anton Paar, Graz, Austria). These samples were placed on the plate of the rheometer, and silicone oil was added to the outer edge of the samples to prevent moisture evaporation.

To study the stability of the $\mathrm{Ti}_{3} \mathrm{C}_{2}$ nanoparticles and hydrogel sample, $\mathrm{Ti}_{3} \mathrm{C}_{2}$ nanoparticles $(50 \mu \mathrm{g} / \mathrm{ml})$ and $\mathrm{Ti}_{3} \mathrm{C}_{2}-\mathrm{Gel}\left(\mathrm{Ti}_{3} \mathrm{C}_{2}\right.$ : $50 \mu \mathrm{g} / \mathrm{ml} ; 20 \% \mathrm{~F} 127 \mathrm{Gel}$ ) were stored at $4^{\circ} \mathrm{C}$. The samples were diluted with pure water before and after storage. Changes in the size of the $\mathrm{Ti}_{3} \mathrm{C}_{2}$ nanoparticles and $\mathrm{Ti}_{3} \mathrm{C}_{2}$-Gel were measured using a particle sizing system.

\section{Assessment of Photothermal Properties}

To evaluate the photothermal conversion capability of $\mathrm{Ti}_{3} \mathrm{C}_{2}$ nanoparticles aqueous solution and $\mathrm{Ti}_{3} \mathrm{C}_{2}$-Gel, 1-ml samples were separately added to different centrifuge tubes and then exposed to an $808-\mathrm{nm}$ NIR laser $\left(1 \mathrm{~W} / \mathrm{cm}^{2}\right)$. A thermal imaging system (FOTRIC, Allen, TX, USA) was used to record the changes in temperature of the samples.

To further evaluate the stability of photothermal conversion, $1 \mathrm{ml} \mathrm{Ti}_{3} \mathrm{C}_{2}$ nanoparticle solution $\left(\mathrm{Ti}_{3} \mathrm{C}_{2}: 50 \mu \mathrm{g} / \mathrm{ml}\right)$ and $\mathrm{Ti}_{3} \mathrm{C}_{2}-\mathrm{Gel}$ $\left(\mathrm{Ti}_{3} \mathrm{C}_{2}: 50 \mu \mathrm{g} / \mathrm{ml} ; 20 \% \mathrm{~F} 127 \mathrm{Gel}\right)$ were separately placed into different tubes and then exposed to the NIR laser $\left(1 \mathrm{~W} / \mathrm{cm}^{2}\right)$. After the samples had naturally cooled to room temperature $\left(20^{\circ} \mathrm{C}-30^{\circ} \mathrm{C}\right)$, they were repeatedly exposed to laser light. We used thermal imaging cameras to record the temperature increase in the samples, which was used to plot a curve of photothermal stability.

\section{In vitro Cytotoxicity}

The cytotoxicity of $\mathrm{Ti}_{3} \mathrm{C}_{2}$ was evaluated using the standard CCK8 assay. $4 \mathrm{~T} 1$ cells were seeded at a density of $5 \times 10^{3}$ cells/well in 96-well plates $\left(37^{\circ} \mathrm{C}, 5 \% \mathrm{CO}_{2}\right)$. After $12 \mathrm{~h}$ of incubation, various concentrations of $\mathrm{Ti}_{3} \mathrm{C}_{2}(400,200,100,50$, and $25 \mu \mathrm{g} / \mathrm{ml})$ were dispersed into fresh DMEM and inoculated into the wells. Cells without $\mathrm{Ti}_{3} \mathrm{C}_{2}$ were used as controls. After incubation for another $24 \mathrm{~h}$, the cells were washed with PBS three times. The absorbance of the cells was measured at $450 \mathrm{~nm}$ using a microplate reader. Each group was analyzed in triplicate.

To evaluate the photothermal therapeutic effects of $\mathrm{Ti}_{3} \mathrm{C}_{2}$ in vitro on tumor cells, 4T1 cells were seeded into 96-well plates $\left(5 \times 10^{3}\right.$ cells/well) and incubated overnight at $37^{\circ} \mathrm{C}$ in a $5 \% \mathrm{CO}_{2}$ atmosphere. Next, $\mathrm{Ti}_{3} \mathrm{C}_{2}$ nanoparticles were added to the wells at final concentrations of 25,50,100,200, and $400 \mu \mathrm{g} / \mathrm{ml}$. The cells were exposed to an 808-nm NIR laser $\left(1 \mathrm{~W} / \mathrm{cm}^{2}\right)$ for $1 \mathrm{~min}$, with untreated $4 \mathrm{~T} 1$ cells used as a control. The cells were incubated for a further $24 \mathrm{~h}$. The $\mathrm{Ti}_{3} \mathrm{C}_{2}$ nanoparticles were removed and washed with PBS. Cell viability was measured at $450 \mathrm{~nm}$ following the instructions for CCK-8.

\section{In vivo Antitumor Performance}

To prepare a $4 \mathrm{~T} 1$ tumor-bearing mouse model, $1 \times 10^{6} 4 \mathrm{~T} 1$ cells were administered subcutaneously into the right armpit of BALB/ c mice (female, 6-8 weeks old). When the tumor volume reached approximately $100 \mathrm{~mm}^{3}$, 4T1 tumor-bearing mice were used for in vivo therapy experiments. The mice were randomly divided into nine groups ( $n=5$ /group): mock (untreated), PBS, Pluronic F127 Gel, $\mathrm{Ti}_{3} \mathrm{C}_{2}, \mathrm{Ti}_{3} \mathrm{C}_{2}$-Gel, PBS + NIR, Gel + NIR, $\mathrm{Ti}_{3} \mathrm{C}_{2}+\mathrm{NIR}$, and $\mathrm{Ti}_{3} \mathrm{C}_{2}-\mathrm{Gel}+\mathrm{NIR}\left(\mathrm{Ti}_{3} \mathrm{C}_{2}: 50 \mu \mathrm{g} / \mathrm{ml}\right.$; Pluronic F127 Gel: 20\%). At day $1,30 \mu \mathrm{l}$ of different preparations was administered into the tumor in mice. After the mice were anesthetized, the tumors were exposed to an $808-\mathrm{nm}$ NIR laser at $1 \mathrm{~W} / \mathrm{cm}^{2}$ for 2 min on days 1 , 3 , and 5 . The length and width of the tumors were measured every other day. Moreover, the body weights of mice were recorded to map the curve of weight-time changes. The tumor volume was calculated according to the following formula: volume $=$ length $\times$ $\left(\right.$ width $\left.^{2}\right) / 2$. All mice were sacrificed on day 15, and the tumors were collected to evaluate the therapeutic effect of PTT in vivo.

\section{In vivo Safety Evaluation}

Blood was collected from anesthetized mice, and the blood samples were placed at room temperature for $2 \mathrm{~h}$ and centrifuged at $1,000 \times \mathrm{g}$ for $20 \mathrm{~min}$ to isolate the serum. Blood biochemistry indicators were detected using a BS-180 automatic biochemical analyzer (Mindray, Shenzhen, China). The tumors were collected for H\&E and TUNEL staining to evaluate the toxicity of the treatment.

\section{Statistical Analysis}

Quantitative data are expressed as the mean \pm standard deviation. Statistical analyses were performed using GraphPad Prism version 8.0 software (GraphPad, Inc, La Jolla, CA, USA). Student's $t$-test and one-way analysis of variance were used to test the significance of differences. Statistical significance was set at $p<0.05\left({ }^{*} p<0.05,{ }^{* *} p<0.01\right)$.

\section{RESULTS AND DISCUSSION}

\section{Characterization of $\mathrm{Ti}_{3} \mathrm{C}_{2}$ and $\mathrm{Ti}_{3} \mathrm{C}_{2}$-Gel}

As shown in Figure 2A, the $\mathrm{Ti}_{3} \mathrm{C}_{2}$ MXene solution existed as a two-dimensional flaky substance. After ultrasonic destruction, the flaky structure disintegrated into uniform shuttle-shaped nanoparticles with a size of nearly $50-100 \mathrm{~nm}$, as revealed by transmission electron microscopy (Figure 2B). The particle size of the $\mathrm{Ti}_{3} \mathrm{C}_{2}$-Gel was approximately $100-200 \mathrm{~nm}$, which was larger than that of the $\mathrm{Ti}_{3} \mathrm{C}_{2}$ nanoparticles (Figure 2C). The results in Figure 2C show that the F127 hydrogels were coated on the surface of the $\mathrm{Ti}_{3} \mathrm{C}_{2}$ nanoparticles. Scanning electron microscopy images showed that the blank F127 hydrogels had a loose and porous structure along with a three-dimensional network (Figure 2D). The main elemental compositions of the $\mathrm{Ti}_{3} \mathrm{C}_{2}$-Gel were $\mathrm{Ti}, \mathrm{C}$, and $\mathrm{O}$, suggesting the formation of composites (Figure 2E). Therefore, F127 hydrogels have the potential to easily accommodate large amounts of nanoparticles. In addition, the particle sizes of $\mathrm{Ti}_{3} \mathrm{C}_{2}$ and $\mathrm{Ti}_{3} \mathrm{C}_{2}$-Gel were measured using dynamic light scattering, 


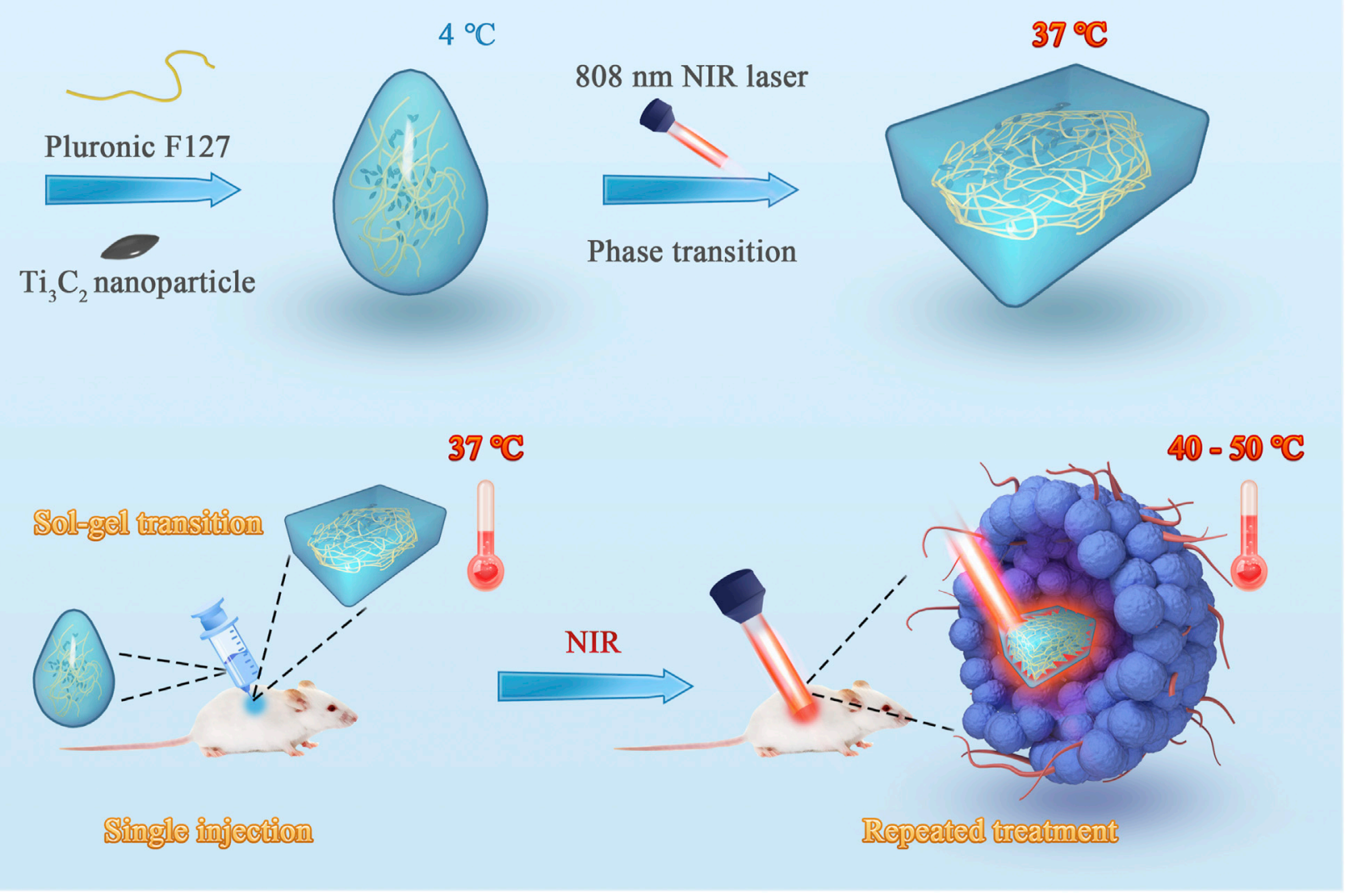

FIGURE 1 | Schematic illustration of the fabrication of the injectable hydrogel system with excellent photo-heat transition capacity. This system was fabricated using a one-step synthesis method. $\mathrm{Ti}_{3} \mathrm{C}_{2}$ nanoparticles and thermosensitive Pluronic $\mathrm{F} 127$ were mixed to prepare the photothermal agent-embedded hydrogel system. The system can form in situ gel in tumor tissue through sol-gel transition and prolong the retention of $\mathrm{Ti}_{3} \mathrm{C}_{2}$ nanoparticles. Using near-infrared laser irradiation, repeated treatments can be achieved with a single injection.

which corroborated the scanning electron microscopy results (Figure 2F). All zeta potential values of the $\mathrm{Ti}_{2}$ nanoparticles, $\mathrm{F} 127$ hydrogels, and $\mathrm{Ti}_{3} \mathrm{C}_{2}$-Gel were positive. To assess the stability of the PTA, the $\mathrm{Ti}_{3} \mathrm{C}_{2}$ nanoparticles and $\mathrm{Ti}_{3} \mathrm{C}_{2^{-}}$ Gel were stored at $4^{\circ} \mathrm{C}$ for 2 weeks and examined for changes in particle size (Figure 2H). The results showed that hydrogels are excellent drug reservoirs, and the samples had a stable particle size, indicating that they are suitable for long-term storage.

\section{Temperature-Sensitive Characteristics of $\mathrm{Ti}_{3} \mathrm{C}_{2}$-Gel}

Figure $3 \mathrm{~A}$ shows images of the blank $\mathrm{F} 127$ hydrogel and $\mathrm{Ti}_{3} \mathrm{C}_{2}-\mathrm{Gel}$ at two different temperatures $\left(4^{\circ} \mathrm{C}\right.$ and $\left.37^{\circ} \mathrm{C}\right)$. Both samples were liquids at low temperatures and presented injectable features. They changed to semisolids at $37^{\circ} \mathrm{C}$ and did not flow even when inverted, which may prolong the retention time of the $\mathrm{Ti}_{3} \mathrm{C}_{2}$ nanoparticles in the tissue. By test tube inversion in a water bath at $37^{\circ} \mathrm{C}$, the time required for the gels to convert from a sol to a gel was $21 \pm 1 \mathrm{~s}$. Doping nanoparticles in the gel did not affect the reversible sol-gel transition of the F127 hydrogel. Observation of the samples showed that the nanoparticles were evenly distributed in the F127 hydrogel matrix. To further explain the temperature-sensitive characteristics of the F127 hydrogels, in vitro experiments were conducted to determine the phase transition temperature and rheological performance of the hydrogels. The phase transition temperature is the temperature at which the hydrogel changes from a sol state to a gel state and is among the most important evaluation indicators for temperature-sensitive hydrogels. The phase transition temperatures of the F127 hydrogels differed at different concentrations. As shown in Figures 3B,C, the phase transition temperatures of $\mathrm{F} 127$ hydrogels and $\mathrm{Ti}_{3} \mathrm{C}_{2}$-Gel increased with decreasing concentrations, and $\mathrm{Ti}_{3} \mathrm{C}_{2}$ had no obvious effect on the phase transition temperature of F127 hydrogels. When the concentration of F127 hydrogels was $18 \%$ and $19 \%$, the phase transition temperatures were $36.3 \pm 0.245^{\circ} \mathrm{C}$ and $29.0 \pm 0.294^{\circ} \mathrm{C}$, respectively. Although the phase transition temperature at an F127 hydrogel concentration of $18 \%$ was closer to the human body temperature, in the experiment, 18\% and 19\% F127 hydrogels were observed to form a second sol state at temperatures greater than $40^{\circ} \mathrm{C}$. When the concentration of F127 hydrogels was less than $20 \%$, the kinetic energy of the colloidal particles increased with increasing temperature and accelerated movement speed. Thus, the gel state was unstable, and a concentration of $20 \%$ F127 hydrogel 


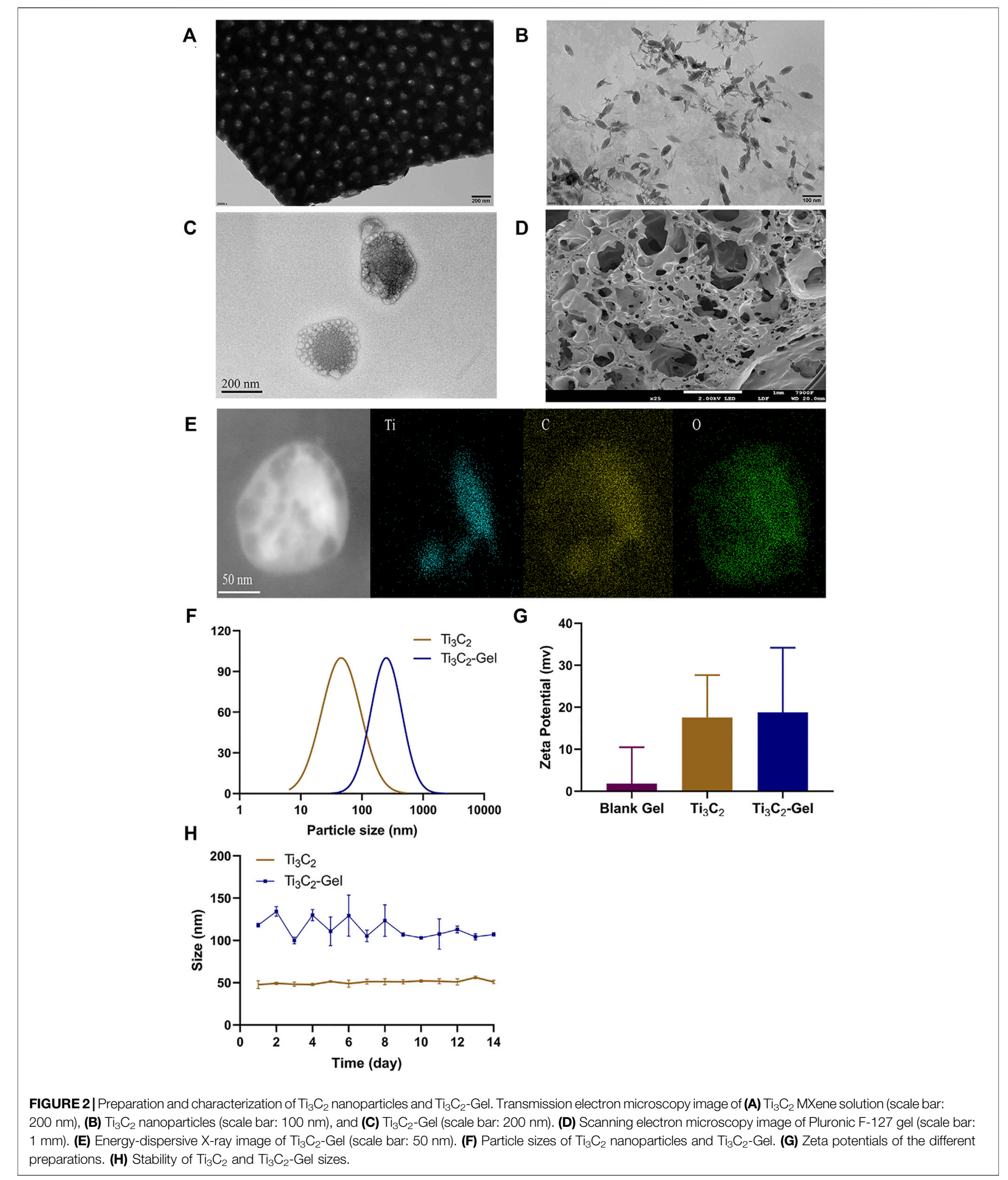

was the best choice. It is beneficial for the blank hydrogel and $\mathrm{Ti}_{3} \mathrm{C}_{2}$-Gel to pass through the syringe needle in a sol state during injection and then quickly transform into a gel state in the body.
Next, the complex rheological performances of the blank hydrogel and $\mathrm{Ti}_{3} \mathrm{C}_{2}$-Gel were detected using a rheometer to draw temperature-viscosity curves (Figures 3D,E). The 

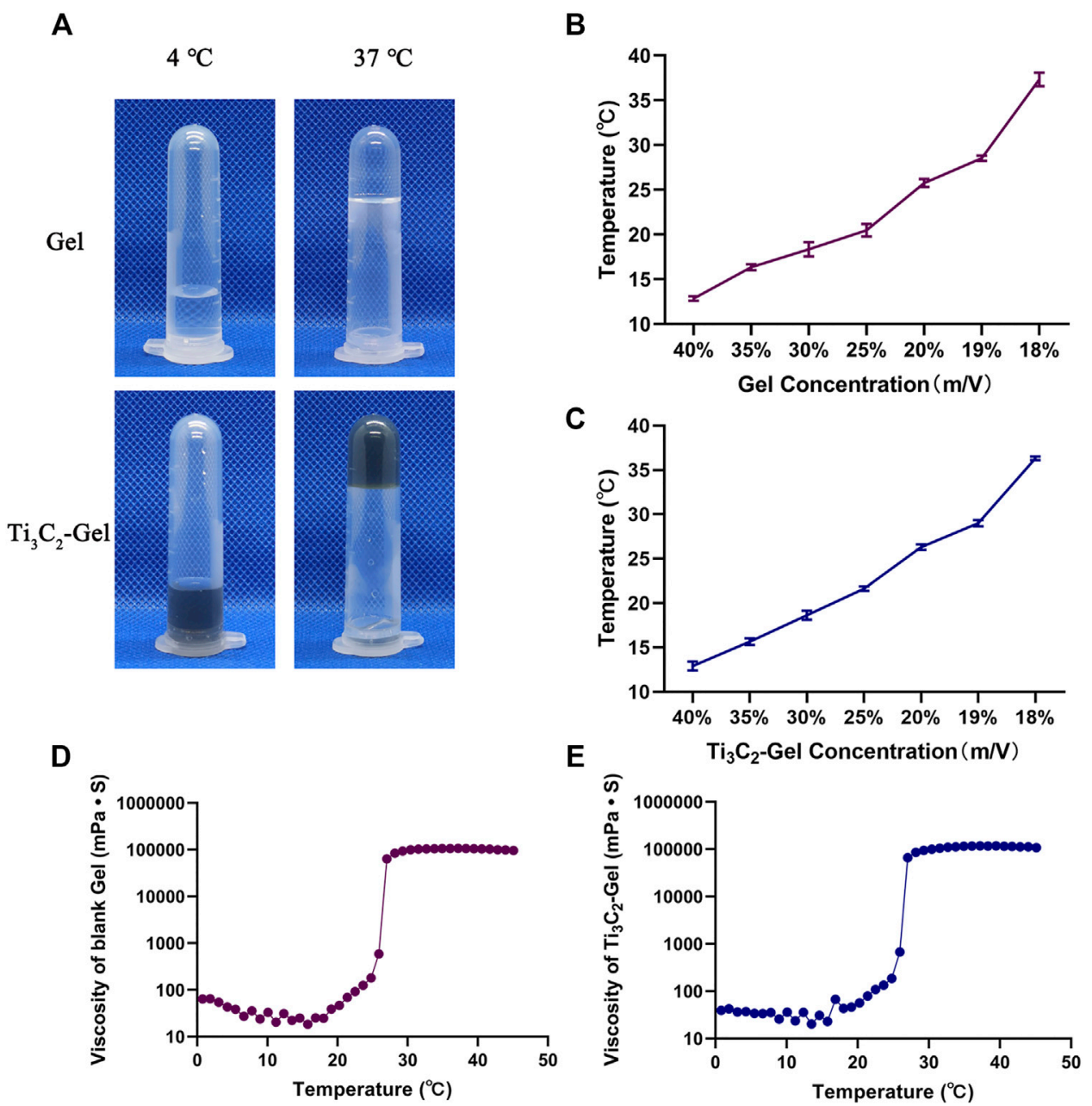

FIGURE 3 | Assessment of photothermal properties. (A) Morphology of Pluronic $\mathrm{F} 127$ gel and $\mathrm{Ti}_{3} \mathrm{C}_{2}-\mathrm{gel}$ at $4^{\circ} \mathrm{C}$ and $37^{\circ} \mathrm{C}$. (B,C) Phase transition temperature of Pluronic F127 gel and $\mathrm{Ti}_{3} \mathrm{C}_{2}$-Gel (concentration of $\mathrm{Ti}_{3} \mathrm{C}_{2}$ was $50 \mathrm{\mu g} / \mathrm{ml}$ ). (D,E) Rheological properties of Pluronic $\mathrm{F}_{12} 7$ and Ti $\mathrm{C}_{2}-\mathrm{gel}$ (concentration of Pluronic $\mathrm{F} 127$ was $20 \%$, and that of $\mathrm{Ti}_{3} \mathrm{C}_{2}$ was $50 \mu \mathrm{g} / \mathrm{ml}$ ).

viscosity profiles of the blank hydrogel and $\mathrm{Ti}_{3} \mathrm{C}_{2}$-Gel showed similar viscosity characteristics, with a phase transition temperature of $25.4^{\circ} \mathrm{C}$, indicating that the $\mathrm{Ti}_{3} \mathrm{C}_{2}$ nanoparticles had negligible effects on the temperature-sensitive performance of F127 hydrogels. The viscosity of the gels was positively correlated with increased temperature. In the phase transition temperature range, the viscosities of the two formulations increased significantly. The F127 hydrogel was in a sol state, with a viscosity of less than $100 \mathrm{mPa}$, ensuring that the entire system was injectable. When the temperature rose to $27^{\circ} \mathrm{C}$, the F127 hydrogel adopted a gel state with a stable viscosity higher than $10,000 \mathrm{mPa} \mathrm{s}$, indicating that a drug reservoir could be formed in the body after local administration.

\section{In vitro Photothermal Performance}

To evaluate the photothermal performance of this hydrogel system, $\mathrm{Ti}_{3} \mathrm{C}_{2}$ nanoparticles and $\mathrm{Ti}_{3} \mathrm{C}_{2}$-Gel were exposed to an 808-nm laser under different conditions (Figures 4A-D). It has been reported that a power of $1 \mathrm{~W} / \mathrm{cm}^{2}$ is the most commonly used safe and effective range (Chen et al., 2019b; Fu et al., 2019; Zhi et al., 2020). The images and temperature changes of these samples were recorded using a thermal imaging system. Based on the heating curve and images, $\mathrm{Ti}_{3} \mathrm{C}_{2}$ and the hydrogel system showed excellent photothermal properties. Under the same irradiation power, the increase in the temperature of samples in the tube was concentration- and time-dependent. In addition, the temperature of the $\mathrm{Ti}_{3} \mathrm{C}_{2}$ nanoparticle solution $(50 \mu \mathrm{g} / \mathrm{ml})$ reached $40^{\circ} \mathrm{C}$, whereas that of the $\mathrm{Ti}_{3} \mathrm{C}_{2}$-Gel system reached $50^{\circ} \mathrm{C}$ after exposure to the NIR laser for $2 \mathrm{~min}$. The $\mathrm{Ti}_{3} \mathrm{C}_{2}$ nanoparticles without encapsulation in the hydrogel were so dispersed that the heat generated was more likely to be lost, whereas the gel system was conducive to the accumulation of $\mathrm{Ti}_{3} \mathrm{C}_{2}$ nanoparticles. In addition, the blank hydrogel exhibited negligible temperature changes under NIR laser exposure.

An excellent PTA must produce constant high temperatures to facilitate repeated photothermal treatment (Figures 4E,F). To evaluate photothermal stability, the $\mathrm{Ti}_{3} \mathrm{C}_{2}$ nanoparticle solution $(50 \mu \mathrm{g} / \mathrm{ml})$ and $\mathrm{Ti}_{3} \mathrm{C}_{2}-\mathrm{Gel}\left(\mathrm{Ti}_{3} \mathrm{C}_{2}: 50 \mu \mathrm{g} / \mathrm{ml}\right.$; Pluronic F127 Gel: 

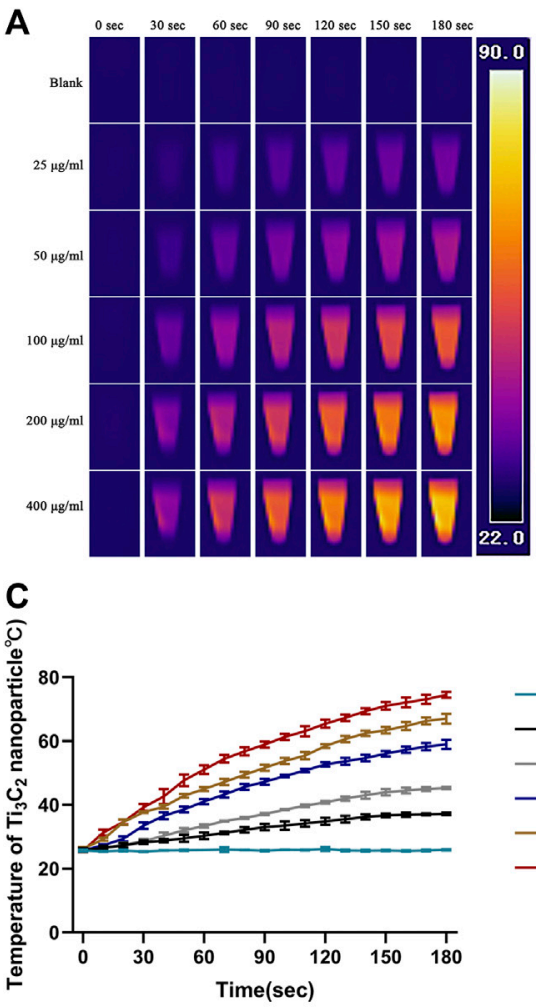

E

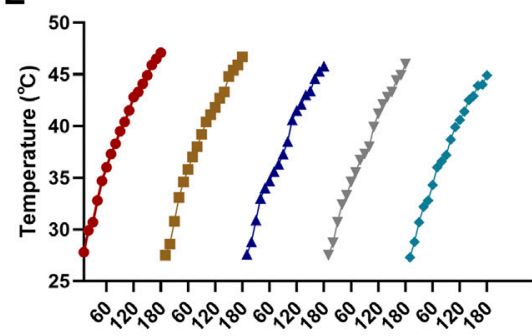

G

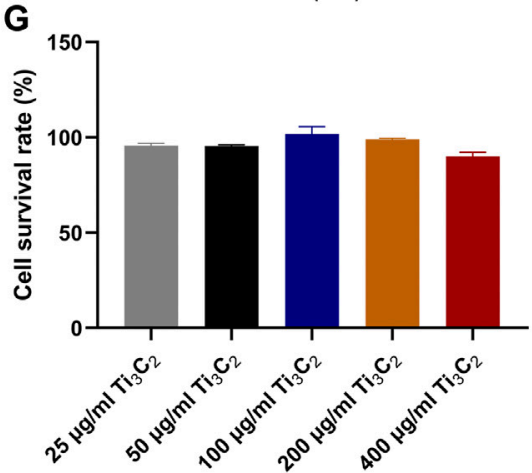

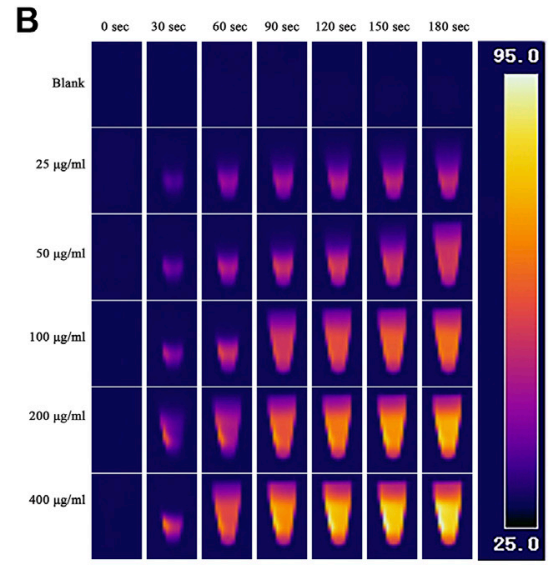

D

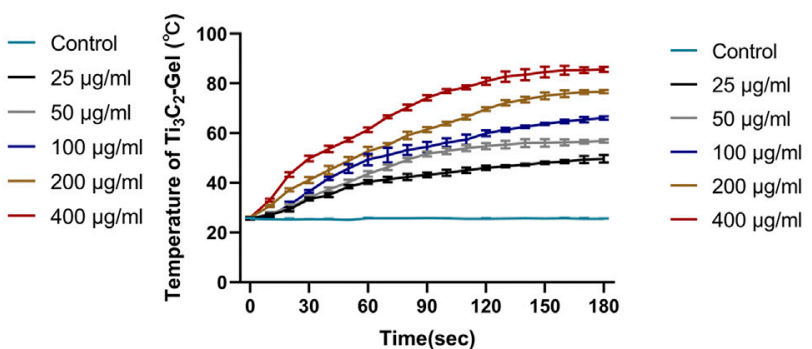

F

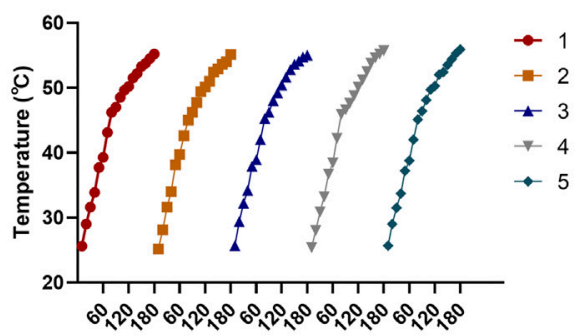

Time (sec)

H

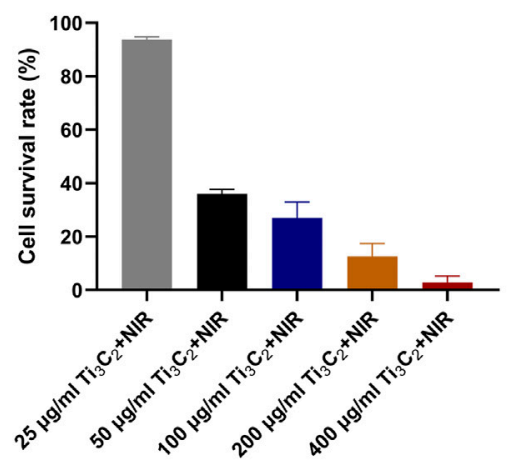

FIGURE 4 | In vitro photothermal performance. (A,B) Temperature diagram of $\mathrm{Ti}_{3} \mathrm{C}_{2}$ nanoparticles and $\mathrm{Ti}_{3} \mathrm{C}_{2}-\mathrm{Gel}_{\mathrm{inder}} 808-\mathrm{nm}$ irradiation (1 W/cm ${ }^{2}$ ). (C,D) Heating curve of different concentrations of $\mathrm{Ti}_{3} \mathrm{C}_{2}$ nanoparticles and $\mathrm{Ti}_{3} \mathrm{C}_{2}$-Gel under 808-nm irradiation $\left(1 \mathrm{~W} / \mathrm{cm}^{2}\right)$. (E,F) Heating curves of Ti ${ }_{3} \mathrm{C}_{2}$ nanoparticles and $\mathrm{Ti}_{3} \mathrm{C}_{2}$-Gel treated with repeated 808-nm irradiation $\left(1 \mathrm{~W} / \mathrm{cm}^{2}\right)$. (G) Viabilities of $4 \mathrm{~T}_{1}$ cells incubated with different concentrations of Ti $\mathrm{C}_{2}$ nanoparticles in DMEM media for $12 \mathrm{~h}$. (H) Cytotoxicity of $\mathrm{Ti}_{3} \mathrm{C}_{2}$ nanoparticles against $4 \mathrm{~T} 1$ cells exposed to the $808-\mathrm{nm}$ NIR laser $\left(1 \mathrm{~W} / \mathrm{cm}^{2}\right)$ for $1 \mathrm{~min}(n=4 / \mathrm{group})$. 
A

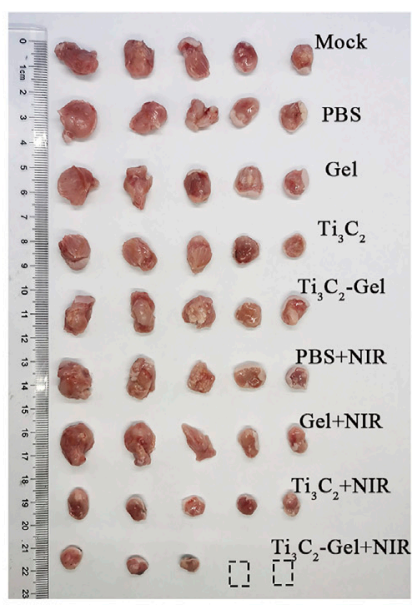

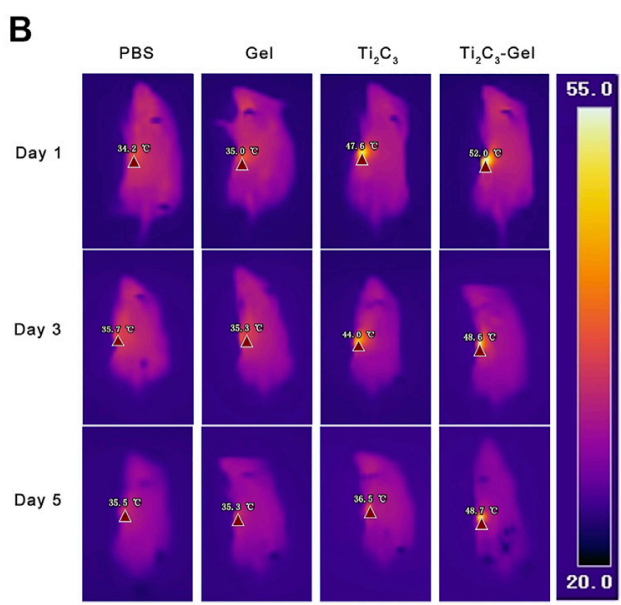

E
C

Day 1

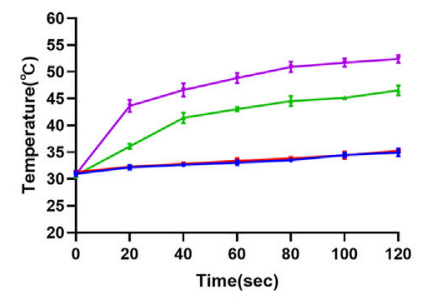

$\mathbf{F}$

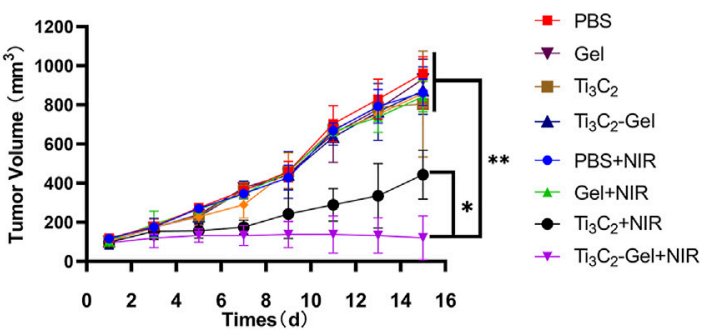

Day 3
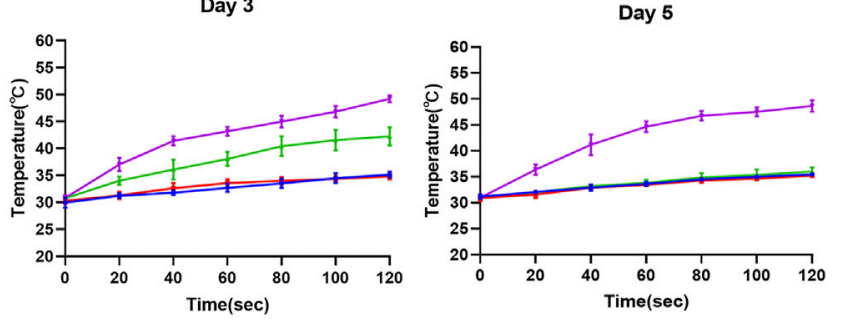

- PBS+NIR

- Gel+NIR

- $\mathrm{Ti}_{3} \mathrm{C}_{2}+\mathrm{NIR}$

- $\mathrm{Ti}_{3} \mathrm{C}_{2}-\mathrm{Gel}+\mathrm{NIR}$
G

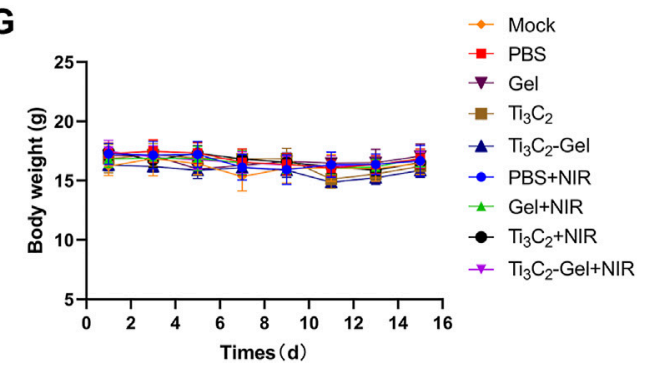

FIGURE 5 | In vivo antitumor performance. (A) Digital images of tumors of mice after treatment. (B) Thermal images of mice irradiated with an 808-nm laser. (C-E) Temperature in tumor-bearing mice recorded by a thermal imager under the 808-nm laser. (F) Growth curves of tumors in all mice after treatment. $n=5 /$ group, mean \pm $\mathrm{SD},{ }^{\star \star} p<0.01$. (G) Average body weight of mice in different groups.

$20 \%)$ were tested by recording heating curves with irradiation $\left(808 \mathrm{~nm}, 1 \mathrm{~W} / \mathrm{cm}^{2}\right)$. The temperature of both $\mathrm{Ti}_{3} \mathrm{C}_{2}$ nanoparticles and $\mathrm{Ti}_{3} \mathrm{C}_{2}$-Gel rapidly reached $45^{\circ} \mathrm{C}$ upon NIR irradiation. The photothermal performance of the $\mathrm{Ti}_{3} \mathrm{C}_{2}$ nanoparticles and $\mathrm{Ti}_{3} \mathrm{C}_{2^{-}}$ Gel remained constant over five cycles of repeated laser irradiation, indicating the potential of $\mathrm{Ti}_{3} \mathrm{C}_{2}$-Gel to act as a durable PTA for cancer treatment. The $\mathrm{Ti}_{3} \mathrm{C}_{2}$-Gel system may achieve multiple treatment effects following a single injection.

Based on the above results, the toxicity and photothermal therapeutic efficacy of $\mathrm{Ti}_{3} \mathrm{C}_{2}$ on $4 \mathrm{~T} 1$ cells were investigated in a CCK-8 assay. Figures 4G,H show the survival rate of $4 \mathrm{~T} 1$ cells against different treatments for $24 \mathrm{~h}$. As observed in the CCK-8 assay, $\mathrm{Ti}_{3} \mathrm{C}_{2}$ nanoparticles at different concentrations $(25,50,100$, 200 , and $400 \mu \mathrm{g} / \mathrm{ml}$ ) had no obvious lethal effects on $4 \mathrm{~T} 1$ cells. The cell viability rates were all above $90 \%$, suggesting negligible toxicity of the $\mathrm{Ti}_{3} \mathrm{C}_{2}$ nanoparticles. However, cell death was observed after laser exposure $\left(808 \mathrm{~nm}, 1 \mathrm{~W} / \mathrm{cm}^{2}, 1 \mathrm{~min}\right)$. The survival rate of cells varied with the increase in the concentration of $\mathrm{Ti}_{3} \mathrm{C}_{2}$ nanoparticles under the same laser output power. As the concentration of $\mathrm{Ti}_{3} \mathrm{C}_{2}$ nanoparticles increased, the survival rate of the cells decreased. At a concentration of $50 \mu \mathrm{g} / \mathrm{ml}$, most tumor cells were killed, exhibiting an excellent therapeutic effect. Generally, a high concentration of exogenous nanomaterials increases metabolic pressure on animals. To prepare materials economically and safely, and from the perspective of animal welfare, we chose the lowest effective drug concentration.

\section{In vivo Antitumor Performance}

Encouraged by the above results, we further evaluated the photothermal antitumor efficacy of $\mathrm{Ti}_{3} \mathrm{C}_{2}$-Gel in $4 \mathrm{~T} 1$ tumorbearing mouse models. After the tumors reached $100 \mathrm{~mm}^{3}$ in size, the $4 \mathrm{~T} 1$ tumor-bearing mice were randomly divided into nine 


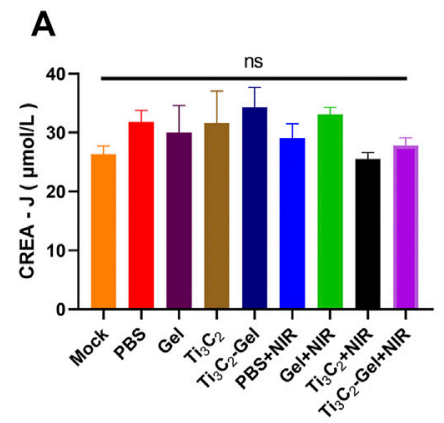

B

D

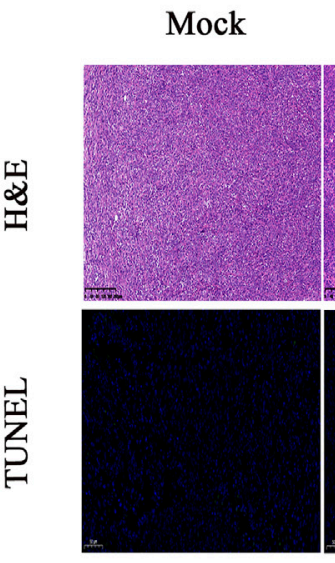

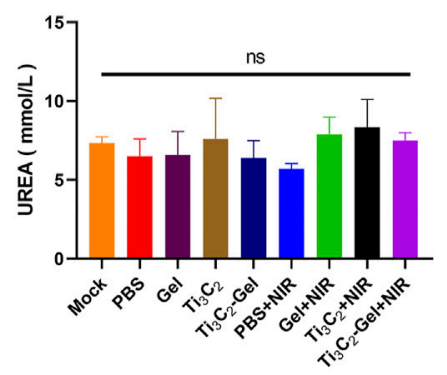

PBS
C

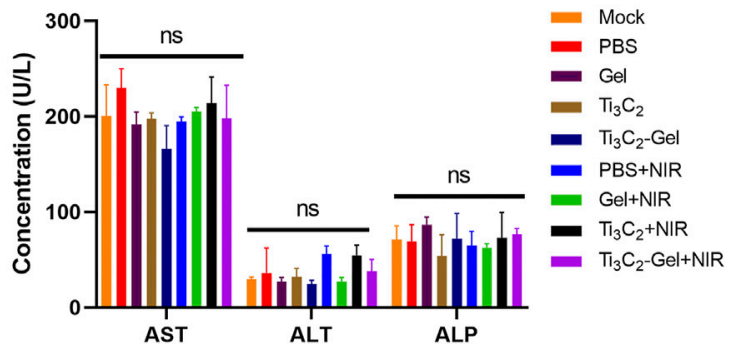

$\mathrm{Ti}_{3} \mathrm{C}_{2}-\mathrm{Gel}$

PBS+NIR

Gel+NIR

$\mathrm{Ti}_{3} \mathrm{C}_{2}+\mathrm{NIR}$

$\mathrm{Ti}_{3} \mathrm{C}_{2}$-Gel+NIR
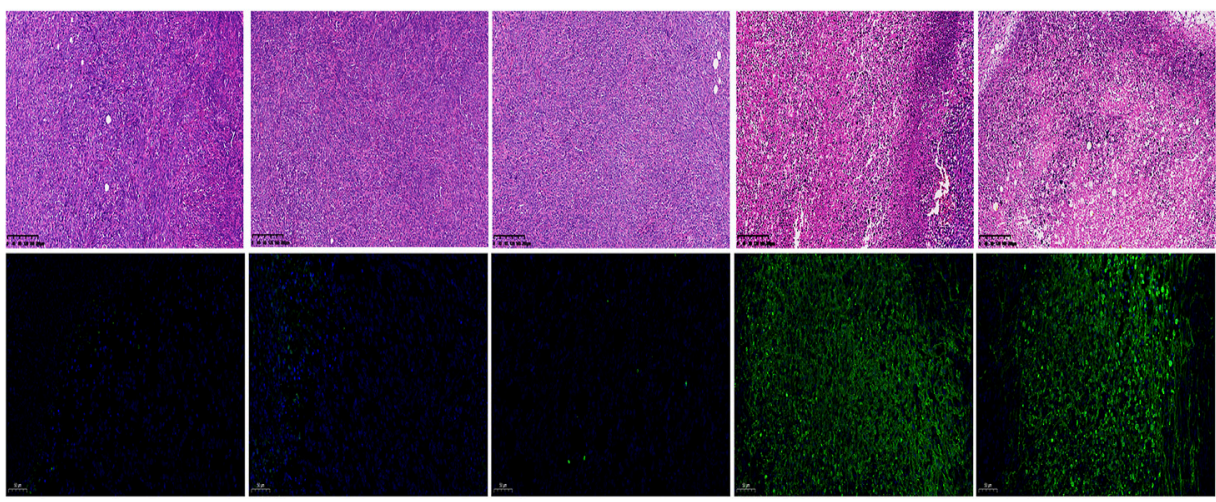

FIGURE 6 | In vivo safety evaluation. (A-C) Blood biochemistry analysis (including indicators of liver and kidney function) of mice after various treatments. $n=3$ / group, mean \pm SD. (D) Hematoxylin and eosin staining and TUNEL staining of tumor sections from different treatment groups.

groups: mock, PBS, Pluronic F127 $\mathrm{Gel}, \mathrm{Ti}_{3} \mathrm{C}_{2}$ aqueous solution, $\mathrm{Ti}_{3} \mathrm{C}_{2}$-Gel, PBS + NIR, Pluronic F127 Gel + NIR, $\mathrm{Ti}_{3} \mathrm{C}_{2}$ aqueous solution + NIR, and $\mathrm{Ti}_{3} \mathrm{C}_{2}-\mathrm{Gel}+\mathrm{NIR}$. To determine the advantages of the gel system, we used thermal imaging to record the temperature generated upon laser exposure. NIR treatment was performed on days 1,3 , and 5 ; at 2 weeks after treatment, all tumor tissues were collected to evaluate antitumor efficacy. Notably, upon treatment with $\mathrm{Ti}_{3} \mathrm{C}_{2}+\mathrm{NIR}$ and $\mathrm{Ti}_{3} \mathrm{C}_{2}$-Gel + NIR, tumor growth was significantly suppressed (Figures $\mathbf{5 A}, \mathrm{F})$. The tumor tissues treated with the $\mathrm{Ti}_{3} \mathrm{C}_{2}$ nanoparticles and $\mathrm{Ti}_{3} \mathrm{C}_{2}$-Gel were smaller than those of the control groups. Using a thermal camera, we observed that the $\mathrm{Ti}_{3} \mathrm{C}_{2}+\mathrm{NIR}$ group reached the desired therapeutic temperature upon irradiation at $808 \mathrm{~nm}$ at the beginning of the experiment. However, the nanoparticles did not reach the initial high temperature over time, similar to the observations in the other control groups. In contrast, $\mathrm{Ti}_{3} \mathrm{C}_{2}+\mathrm{NIR}$ treatment led to a high temperature during the long treatment period (Figures 5B-E). Interestingly, some tumor tissues faded away at the end of treatment with $\mathrm{Ti}_{3} \mathrm{C}_{2}$-Gel and NIR radiation. During the treatment, the temperature of the 
tumor tissues increased to $50^{\circ} \mathrm{C}$ within $2 \mathrm{~min}$, which can disrupt the cell membranes of cancer cells; the underlying mechanisms resulting from PTT have been reported as follows: 1) inhibition of DNA, RNA, and protein synthesis at high temperatures; 2) changes in cell membrane permeability; 3) induction of immunogenic death of cancer cells due to the release of tumor-specific antigens; and 4) production of blood vessel spasms that result in intravascular thrombosis of tumor tissue (Liu et al., 2019b; Poursalehi et al., 2019; Ye et al., 2019; Shang et al., 2020; Chang et al., 2021; Li et al., 2021).

These superior antitumor effects were verified by $H \& E$ and TUNEL staining of the tumor sections (Figure 6D). The tumor tissues in the $\mathrm{Ti}_{3} \mathrm{C}_{2}$-Gel + NIR group showed more obvious histological damage compared to the typical tumor structure in other groups, such as partial tumor destruction and necrotic response, indicating significant apoptosis. The body weights of the mice were measured to evaluate the systemic toxicity of the treatments. No obvious body weight loss was observed in these groups during treatment, indicating the biocompatibility of the $\mathrm{Ti}_{3} \mathrm{C}_{2}$ and $\mathrm{F} 127$ hydrogels (Figure 5G). In addition, the indicators of liver and kidney function in all mice were detected using a biochemical analyzer. The blood biochemical indicators of mice treated with $\mathrm{Ti}_{3} \mathrm{C}_{2}$-Gel showed no obvious differences from those of other control groups, suggesting healthy liver and kidney functions (Figures 6A-C). Similar to previously reported results (Chen et al., 2019a; Fu et al., 2019; Qin et al., 2019), the F127 hydrogel delayed the release of the loaded drug and avoided accumulated toxicity. The in vivo results reveal the potential of the $\mathrm{Ti}_{3} \mathrm{C}_{2}$-Gel system to exert photothermal therapeutic effects with high biocompatibility and biosafety.

\section{CONCLUSION}

In summary, we constructed an injectable and biodegradable theranostic system based on $\mathrm{Ti}_{3} \mathrm{C}_{2}$ nanoparticles and $\mathrm{Ti}_{3} \mathrm{C}_{2}$-Gel for robust PTT. The $\mathrm{Ti}_{3} \mathrm{C}_{2}$ nanoparticle showed a shuttle structure with a diameter of approximately $50 \mathrm{~nm}$, making it useful as a PTA for PTT. As a thermosensitive hydrogel approved by the FDA, F127 is combined with $\mathrm{Ti}_{3} \mathrm{C}_{2}$ nanoparticles to form a

\section{REFERENCES}

Chang, M., Hou, Z., Wang, M., Li, C., and Lin, J. (2021). Recent Advances in Hyperthermia Therapy-Based Synergistic Immunotherapy. Adv. Mater. 33 (4), e2004788. doi:10.1002/adma.202004788

Chen, J., Ning, C., Zhou, Z., Yu, P., Zhu, Y., Tan, G., et al. (2019). Nanomaterials as Photothermal Therapeutic Agents. Prog. Mater. Sci. 99, 1-26. doi:10.1016/ j.pmatsci.2018.07.005

Chen, Y., Khan, A. R., Yu, D., Zhai, Y., Ji, J., Shi, Y., et al. (2019). Pluronic F127Functionalized Molybdenum Oxide Nanosheets with $\mathrm{pH}$-dependent Degradability for Chemo-Photothermal Cancer Therapy. J. Colloid Interf. Sci. 553, 567-580. doi:10.1016/j.jcis.2019.06.066

Chen, Y., Li, H., Deng, Y., Sun, H., Ke, X., and Ci, T. (2017). Near-infrared Light Triggered Drug Delivery System for Higher Efficacy of Combined Chemo-Photothermal Treatment. Acta Biomater. 51, 374-392. doi:10.1016/j.actbio.2016.12.004

Fu, J., Wu, B., Wei, M., Huang, Y., Zhou, Y., Zhang, Q., et al. (2019). Prussian Blue Nanosphere-Embedded In Situ Hydrogel for Photothermal Therapy by versatile photothermal gel system through a simple mixture. In addition, in vivo and in vitro experiments showed that the gel system has an excellent therapeutic effect against breast cancer. The $\mathrm{Ti}_{3} \mathrm{C}_{2}$-Gel can elevate the temperature of tumor tissues to ablate $4 \mathrm{~T} 1$ cancer cells upon relatively mild laser exposure $\left(40-50^{\circ} \mathrm{C}\right)$. The $\mathrm{Ti}_{3} \mathrm{C}_{2}$-Gel system not only has excellent photoheat conversion and photothermal stability under repeated irradiation but also can form gels in situ in the body to increase the retention time and reduce the toxic side effects of the nanoparticles. As a result, this injectable $\mathrm{Ti}_{3} \mathrm{C}_{2}$-Gel system provides a translational paradigm for the photothermal treatment of breast cancer.

\section{DATA AVAILABILITY STATEMENT}

The raw data supporting the conclusion of this article will be made available by the authors, without undue reservation.

\section{ETHICS STATEMENT}

The animal study was reviewed and approved by The First Affiliated Hospital, and College of Clinical Medicine of Henan University of Science and Technology.

\section{AUTHOR CONTRIBUTIONS}

JY and CZ contributed equally to this work. JY and QM conceived and organized the project. $\mathrm{CZ}$ and $\mathrm{QM}$ completed the experimental part. CZ was responsible for writing the paper. SG and TP collected and summarized the relevant literature. SG provided fund support and revised this article.

\section{FUNDING}

This work was financially supported by the National Natural Science Foundation of China (81972571).

Peritumoral Administration. Acta Pharmaceutica Sinica B 9 (3), 604-614 doi:10.1016/j.apsb.2018.12.005

Geng, S., Zhao, H., Zhan, G., Zhao, Y., and Yang, X. (2020). Injectable In Situ Forming Hydrogels of Thermosensitive Polypyrrole Nanoplatforms for Precisely Synergistic Photothermo-Chemotherapy. ACS Appl. Mater. Inter. 12 (7), 7995-8005. doi:10.1021/acsami.9b22654

He, R.-X., Wang, Q., Li, B., Jia, J., Lu, W.-J., and Shuang, S.-M. (2020). Construction of Protein-Mediated Copper Sulfide Bonded Mesoporous Silica Nanoparticles Vector for Chemo-Photothermal Synergistic Therapy of Cancer. Chin. J. Anal. Chem. 48 (2), 197-205. doi:10.1016/s1872-2040(19) 61216-8

He, W., Jiang, Y., Li, Q., Zhang, D., Li, Z., and Luan, Y. (2019). A Versatile Strategy to Create an Active Tumor-Targeted Chemo-Photothermal Therapy Nanoplatform: A Case of an IR-780 Derivative Co-assembled with Camptothecin Prodrug. Acta Biomater. 84, 356-366. doi:10.1016/ j.actbio.2018.11.049

Jiang, K., Zhang, L., Hu, Q., Yue, D., Zhang, J., Zhang, X., et al. (2018). Indocyanine green-encapsulated Nanoscale Metal-Organic Frameworks for Highly Effective 
Chemo-Photothermal Combination Cancer Therapy. Mater. Today Nano 2, 50-57. doi:10.1016/j.mtnano.2018.09.001

Li, J., Zhang, W., Ji, W., Wang, J., Wang, N., Wu, W., et al. (2021). Near Infrared Photothermal Conversion Materials: Mechanism, Preparation, and Photothermal Cancer Therapy Applications. J. Mater. Chem. B 9 (38), 7909-7926. doi:10.1039/d1tb01310f

Liu, B., Sun, J., Zhu, J., Li, B., Ma, C., Gu, X., et al. (2020). Injectable and NIRResponsive DNA-Inorganic Hybrid Hydrogels with Outstanding Photothermal Therapy. Adv. Mater. 32 (39), e2004460. doi:10.1002/adma.202004460

Liu, M., Song, X., Wen, Y., Zhu, J.-L., and Li, J. (2017). Injectable Thermoresponsive Hydrogel Formed by Alginate-GPoly(N-Isopropylacrylamide) that Releases Doxorubicin-Encapsulated Micelles as a Smart Drug Delivery System. ACS Appl. Mater. Inter. 9 (41), 35673-35682. doi:10.1021/acsami.7b12849

Liu, W., Zhang, X., Zhou, L., Shang, L., and Su, Z. (2019). Reduced Graphene Oxide (rGO) Hybridized Hydrogel as a Near-Infrared (NIR)/pH Dual-Responsive Platform for Combined Chemo-Photothermal Therapy. J. Colloid Interf. Sci. 536, 160-170. doi:10.1016/j.jcis.2018.10.050

Liu, Y., Bhattarai, P., Dai, Z., and Chen, X. (2019). Photothermal Therapy and Photoacoustic Imaging via Nanotheranostics in Fighting Cancer. Chem. Soc. Rev. 48 (7), 2053-2108. doi:10.1039/c8cs00618k

Lu, H., Zhao, Q., Wang, X., Mao, Y., Chen, C., Gao, Y., et al. (2020). Multi-stimuli Responsive Mesoporous Silica-Coated Carbon Nanoparticles for ChemoPhotothermal Therapy of Tumor. Colloids Surf. B: Biointerfaces 190, 110941. doi:10.1016/j.colsurfb.2020.110941

Popescu, M.-T., Mourtas, S., Pampalakis, G., Antimisiaris, S. G., and Tsitsilianis, C. (2011). pH-responsive Hydrogel/liposome Soft Nanocomposites for Tuning Drug Release. Biomacromolecules 12 (8), 3023-3030. doi:10.1021/bm2006483

Poursalehi, Z., Salehi, R., Samadi, N., Rasta, S. H., Mansoori, B., and Majdi, H. (2019). A Simple Strategy for Chemo-Photothermal Ablation of Breast Cancer Cells by Novel Smart Gold Nanoparticles. Photodiagnosis Photodynamic Ther. 28, 25-37. doi:10.1016/j.pdpdt.2019.08.019

Qin, L., Ling, G., Peng, F., Zhang, F., Jiang, S., He, H., et al. (2019). Black Phosphorus Nanosheets and Gemcitabine Encapsulated Thermo-Sensitive Hydrogel for Synergistic Photothermal-Chemotherapy. J. Colloid Interf. Sci. 556, 232-238. doi:10.1016/j.jcis.2019.08.058

Rafieerad, A., Yan, W., Sequiera, G. L., Sareen, N., Abu-El-Rub, E., Moudgil, M., et al. (2019). Application of Ti3 C2 MXene Quantum Dots for Immunomodulation and Regenerative Medicine. Adv. Healthc. Mater. 8 (16), e1900569. doi:10.1002/adhm.201900569

Russo, E., and Villa, C. (2019). Poloxamer Hydrogels for Biomedical Applications. Pharmaceutics 11 (12). doi:10.3390/pharmaceutics11120671

Sahu, A., Lee, J. H., Lee, H. G., Jeong, Y. Y., and Tae, G. (2016). Prussian Blue/serum Albumin/indocyanine green as a Multifunctional Nanotheranostic Agent for Bimodal Imaging Guided Laser Mediated Combinatorial Phototherapy. J. Controlled Release 236, 90-99. doi:10.1016/j.jconrel.2016.06.031

Senapati, S., Mahanta, A. K., Kumar, S., and Maiti, P. (2018). Controlled Drug Delivery Vehicles for Cancer Treatment and Their Performance. Sig Transduct Target. Ther. 3, 7. doi:10.1038/s41392-017-0004-3

Shang, T., Yu, X., Han, S., and Yang, B. (2020). Nanomedicine-based Tumor Photothermal Therapy Synergized Immunotherapy. Biomater. Sci. 8 (19), 5241-5259. doi:10.1039/d0bm01158d

Wang, Y., Zhang, H., Xie, J., Liu, Y., Wang, S., and Zhao, Q. (2020). Three Dimensional Mesoporous Carbon Nanospheres as Carriers for ChemoPhotothermal Therapy Compared with Two Dimensional Graphene Oxide
Nanosheets. Colloids Surf. A: Physicochemical Eng. Aspects 590. doi:10.1016/ j.colsurfa.2020.124498

Xu, M., Zhang, K., Liu, Y., Wang, J., Wang, K., and Zhang, Y. (2019). Multifunctional MoS2 Nanosheets with Au NPs Grown In Situ for Synergistic Chemo-Photothermal Therapy. Colloids Surf. B: Biointerfaces 184, 110551. doi:10.1016/j.colsurfb.2019.110551

Ye, X., Liang, X., Chen, Q., Miao, Q., Chen, X., Zhang, X., et al. (2019). Surgical Tumor-Derived Personalized Photothermal Vaccine Formulation for Cancer Immunotherapy. ACS Nano 13 (3), 2956-2968. doi:10.1021/acsnano.8b07371

Yu, J., Wang, J., Zhang, Y., Chen, G., Mao, W., Ye, Y., et al. (2020). Glucoseresponsive Insulin Patch for the Regulation of Blood Glucose in Mice and Minipigs. Nat. Biomed. Eng. 4 (5), 499-506. doi:10.1038/s41551-019-0508-y

Yu, Y., Cheng, Y., Tong, J., Zhang, L., Wei, Y., and Tian, M. (2021). Recent Advances in Thermo-Sensitive Hydrogels for Drug Delivery. J. Mater. Chem. B 9 (13), 2979-2992. doi:10.1039/d0tb02877k

Yu, Y., Zhang, Z., Wang, Y., Zhu, H., Li, F., Shen, Y., et al. (2017). A New NIRTriggered Doxorubicin and Photosensitizer Indocyanine green Co-delivery System for Enhanced Multidrug Resistant Cancer Treatment through Simultaneous Chemo/photothermal/photodynamic Therapy. Acta Biomater. 59, 170-180. doi:10.1016/j.actbio.2017.06.026

Zhang, H., Sun, Y., Huang, R., Cang, H., Cai, Z., and Sun, B. (2018). pH-Sensitive Prodrug Conjugated Polydopamine for NIR-Triggered Synergistic ChemoPhotothermal Therapy. Eur. J. Pharmaceutics Biopharmaceutics 128, 260-271. doi:10.1016/j.ejpb.2018.05.013

Zhao, P., Jin, Z., Chen, Q., Yang, T., Chen, D., Meng, J., et al. (2018). Local Generation of Hydrogen for Enhanced Photothermal Therapy. Nat. Commun. 9 (1), 4241. doi:10.1038/s41467-018-06630-2

Zhao, T., Qin, S., Peng, L., Li, P., Feng, T., Wan, J., et al. (2019). Novel Hyaluronic Acid-Modified Temperature-Sensitive Nanoparticles for Synergistic ChemoPhotothermal Therapy. Carbohydr. Polym. 214, 221-233. doi:10.1016/ j.carbpol.2019.03.043

Zhi, D., Yang, T., O'Hagan, J., Zhang, S., and Donnelly, R. F. (2020). Photothermal Therapy. J. Controlled Release 325, 52-71. doi:10.1016/j.jconrel.2020.06.032

Zhu, D., Fan, F., Huang, C., Zhang, Z., Qin, Y., Lu, L., et al. (2018). Bubblegenerating Polymersomes Loaded with Both Indocyanine green and Doxorubicin for Effective Chemotherapy Combined with Photothermal Therapy. Acta Biomater. 75, 386-397. doi:10.1016/j.actbio.2018.05.033

Conflict of Interest: The authors declare that the research was conducted in the absence of any commercial or financial relationships that could be construed as a potential conflict of interest.

Publisher's Note: All claims expressed in this article are solely those of the authors and do not necessarily represent those of their affiliated organizations, or those of the publisher, the editors, and the reviewers. Any product that may be evaluated in this article, or claim that may be made by its manufacturer, is not guaranteed or endorsed by the publisher.

Copyright ( $(2021$ Yao, Zhu, Peng, Ma and Gao. This is an open-access article distributed under the terms of the Creative Commons Attribution License (CC BY). The use, distribution or reproduction in other forums is permitted, provided the original author(s) and the copyright owner(s) are credited and that the original publication in this journal is cited, in accordance with accepted academic practice. No use, distribution or reproduction is permitted which does not comply with these terms. 